\title{
Effect of Diet and Dietary Fatty Acids on the Transformation and Incorporation of C18 Fatty Acids in Double-Muscled Belgian Blue Young Bulls
}

\author{
Katleen Raes, ${ }^{*}, \dagger$ Veerle Fievez, ${ }^{\dagger}$ Tsang Tsey Chow,${ }^{\dagger}$ Diana Ansorena, ${ }^{\S}$ \\ Daniel Demeyer, ${ }^{\dagger}$ And StefaAn De SMeT ${ }^{\dagger}$ \\ Department of Animal Production, Faculty of Agricultural and Applied Biological Sciences, \\ Ghent University, Proefhoevestraat 10, 9090 Melle, Belgium, and Department of Food Science and \\ Food Technology, University of Navarra, Irunlarrea s/n, 31008 Pamplona, Spain
}

\begin{abstract}
Three groups of double-muscled Belgian Blue young bulls were fed during different stages of production diets differing in the proportions of linolenic and linoleic acid by including linseed in the concentrate or giving grass silage as main linolenic acid suppliers. Samples of rumen and abomasal contents and of the longissimus thoracis, subcutaneous fat, and liver were taken to analyze the fatty acid pattern with emphasis on the individual trans (t) $\mathrm{C} 18: 1$ fatty acids and cis-9,trans-11 conjugated linoleic acid (c9t11CLA). Trans C18:1 isomers represented up to $20 \mathrm{~g} / 100 \mathrm{~g}$ of total fatty acids in rumen and abomasal contents, whereas the accumulation of C9t11CLA was limited. Total trans C18:1 content in subcutaneous fat and intramuscular fat of the longissimus thoracis comprised 8.4 and 5.2 $\mathrm{g} / 100 \mathrm{~g}$ of total fatty acids, respectively, with $\mathrm{t11C} 18: 1$ being the most abundant one. Compared to rumen contents, subcutaneous and intramuscular fat were enriched in c9t11CLA and contained fewer tC18:1 isomers, resulting in a higher c9t11CLA/t11C18:1 ratio $(0.04,0.22$, and 0.22 , respectively). This result suggests that the endogenous synthesis of C9t11CLA in adipose tissue by the $\Delta^{9}$-desaturase was more important than its ruminal production.
\end{abstract}

KEYWORDS: Beef; conjugated linoleic acid; C18 fatty acids; rumen; trans fatty acids

\section{INTRODUCTION}

The fatty acid composition of ruminant tissues and products is complex because of the fatty acid synthesis by rumen microorganisms as well as by lipolysis followed by hydrogenation of dietary polyunsaturated fatty acids (PUFA). Ruminal microbial lipid metabolism is therefore responsible for a variety of unusual fatty acids in the ruminant tissues such as branchedchain fatty acids, conjugated fatty acids, trans (t) fatty acids, and hydroxy fatty acids (see, for example, the review in ref 1 ).

In the rumen biohydrogenation process, a whole range of intermediates is formed, with conjugated dienes and tC18:1 isomers being the most important ones in the microbial hydrogenation of $\mathrm{C} 18: 2 n-6$ and $\mathrm{C} 18: 3 n-3$ (2) to $\mathrm{C} 18: 0$. Of the tC18:1 isomers $\mathrm{t} 11 \mathrm{C} 18: 1$ is the most abundant one and is formed during the biohydrogenation of both $\mathrm{C} 18: 2 n-6$ and $\mathrm{C} 18$ : $3 n-3$. Besides t11C18:1, other trans isomers (with a double bound on position 4 to 16) are found in rumen contents and ruminant products, formed either by the rumen microorganisms or by double-bond migration $(3-6)$. The $\mathrm{t} 15 \mathrm{C} 18: 1$ isomer is formed as one of the end-products in the hydrogenation of $\mathrm{C} 18$ :

* Corresponding author (telephone + 32926490 04; fax + 329264 90 99; e-mail Katleen.raes@UGent.be).

Ghent University.

$\S$ University of Navarra.
$3 n-3$ (2), whereas under certain rumen conditions the biohydrogenation pathway of $\mathrm{C} 18: 2 n-6$ is shifted toward the production of t10C18:1 rather than $111 \mathrm{C} 18: 1(4,7,8)$. Although tC18:1 isomers are formed during the hydrogenation of both C18:2n-6 and C18:3n-3, Mosley et al. (9) have recently shown that rumen microorganisms are able to form a whole range of tC18:1 isomers from c9C18:1. Conjugated linoleic acid (CLA) isomers seem only to be formed as intermediates in the hydrogenation pathway of $\mathrm{C} 18: 2 n-6$, resulting in predominantly cis-9, trans-11CLA (c9t11CLA) (2) or in t10c12CLA at high concentrate diets in dairy cows (10). Also, other CLA isomers can be found in rumen and duodenal digesta (4), of which the formation pathway is not yet elucidated.

Surprisingly, feeding ruminant diets rich in C18:3n-3 [grass(silage), linseed] increased the c9t11CLA content in the meat and milk $(11-13)$, whereas as mentioned earlier this isomer is not formed in the rumen as an intermediate during the biohydrogenation of $\mathrm{C} 18: 3 n-3$. The c9t11CLA is mainly synthesized endogenously in the mammary gland (10), suggesting that a higher CLA content in ruminant products might result from an increased ruminal outflow of t11C18:1. However, dietary effects on rumen accumulation of tC18:1 fatty acids and CLA isomers have been almost exclusively performed using fistulated lactating cows, and few studies list a detailed profile 
of the individual tC18:1 isomers and the formation of c9t11CLA. Studies reporting such information for meat animals are even more rare.

This study aims to follow the rumen transformations of the dietary fatty acids from analyses of rumen and abomasal contents and subcutaneous, intramuscular and liver fat of slaughtered double-muscled Belgian Blue young bulls. Special attention is given to $\mathrm{C} 18: 0$, the individual tC18:1 isomers, c9t11CLA, C18:2n-6, and C18:3n-3. More detailed data on the intramuscular long-chain fatty acid composition have been published elsewhere (14).

\section{MATERIALS AND METHODS}

Animals. Twenty-three Belgian Blue double-muscled young bulls [336 (SD 50) $\mathrm{kg}$ live weight] were divided into three groups [concentrate $(\mathrm{C})$, grass silage-concentrate (GC), and maize silageconcentrate (MC)] and fed different rations during the last growing, prefattening, and fattening phase, as part of a larger experiment fully discussed by Raes et al. (14). The last growing phase consisted of 70 days; the shift from the prefattening to the fattening phase was based on the live weight of the animals $(\sim 550 \mathrm{~kg})$. Group C (seven animals) and group GC (eight animals) were put on pasture during the last growing phase and were further fattened indoors. Group MC (8 animals) was kept indoors during the whole experimental period. The animals were slaughtered at an average live weight of 681 (SD 30) kg.

Experimental Design and Diets. In brief, the diets of the feeding groups differed according to the three different phases. All groups were fed cereal and beet pulp based concentrates, with straw, fresh grass, grass silage, or maize silage as roughage. Linseed was added as the predominant $n-3$ PUFA source in the concentrate. Within the prefattening and fattening phases, diets were formulated on an equal energy and protein base for all groups, and diets were composed to contain predominantly $n-3$ or $n-6$ dietary PUFA at different phases of production. All animals had free access to straw. During the whole experimental period, the groups were receiving the following diets:

(1) Group C shifted from a predominantly $n-3$ diet during the last growing and prefattening phase [linseed in the concentrates in combination respectively with fresh grass (pasture) or whole triticale silage as a roughage] to a predominantly $n-6$ concentrate (without linseed) in the fattening phase.

(2) Group GC received a predominantly $n-3$ diet during the whole experimental period (incorporation of linseed in the concentrate in all phases in combination with fresh grass or grass silage).

(3) Group MC shifted from a predominantly $n-6$ diet (containing no linseed in the concentrates and maize silage as roughage during the last growing and prefattening phase) to a predominantly $n-3$ diet in the fattening phase as linseed was included in the concentrate in combination with maize silage as roughage.

Sampling. Feed samples were obtained on two separate days during each feeding period. The different feeds were vacuum packed and stored at $-18{ }^{\circ} \mathrm{C}$. Samples of rumen and abomasal contents were taken at slaughter of the nonfasted animals, immediately after carcass evisceration. Both rumen and abomasal contents were thoroughly mixed manually before samples were taken $(1$ and $0.5 \mathrm{~L}$ for rumen and abomasal contents, respectively). Digestive content samples were filled in appropriate bottles and kept at $-18{ }^{\circ} \mathrm{C}$, until further analysis. The small lobe of the liver was sampled immediately after slaughter, vacuum packed, and stored at $-18{ }^{\circ} \mathrm{C}$. After the carcasses had been cooled for $24 \mathrm{~h}$ post-mortem, samples of the longissimus thoracis (LT) $(11-12$ th rib) and subcutaneous fat (at the 11-12th rib) were taken on the left side of the carcass. All samples were immediately vacuum packed and frozen at $-18{ }^{\circ} \mathrm{C}$ until analysis.

Analyses. 1. Total Fatty Acid Profiles. Feeds were ground before the fatty acids were extracted. Digestive contents were first lyophilized and ground before further analysis. Liver and meat samples were minced after removal of visible fat, and connective tissue was removed from subcutaneous fat samples before mincing. Fatty acids of the different samples were extracted using chloroform/methanol (2:1, v/v), adapted from the method of Folch et al. (15), and analyzed by gas chromatog- raphy as described by Raes et al. (16). Briefly, fatty acids were methylated using $\mathrm{NaOH} / \mathrm{MeOH}$ followed by $\mathrm{HCl} / \mathrm{MeOH}$. The methylated fatty acids were analyzed on an HP6890 gas chromatograph (Brussels, Belgium) with a CP-Sil88 column for FAME $(100 \mathrm{~m} \times 0.25$ $\mathrm{mm} \times 0.2 \mu \mathrm{m}$; Chrompack, Middelburg, The Netherlands). The following temperature program was used: $150{ }^{\circ} \mathrm{C}$ during $2 \mathrm{~min}$ followed by an increase of $1^{\circ} \mathrm{C} / \mathrm{min}$ to $200^{\circ} \mathrm{C}$, followed by an increase of $5{ }^{\circ} \mathrm{C} / \mathrm{min}$ to $215{ }^{\circ} \mathrm{C}$. Peaks were identified on the basis of their retention times, corresponding with the standards (Sigma, Bornem, Belgium, and NuChek Prep., Elysian, MN).

2. Profile of the C18:1 Isomers. After methylation, fatty acids were further separated on $\mathrm{Ag}^{+}$thin-layer chromatography to separate the individual tC18:1 isomers, based on the description given by Christie (17). Plates covered with silica gel G (Fluka, Bornem, Belgium), were impregnated with $\mathrm{Ag}^{+}$ions by dipping the plates in a $1 \% \mathrm{AgNO}_{3}$ solution in $\mathrm{MeOH}$. After the plates had been activated $\left(1 \mathrm{~h}\right.$ at $\left.103^{\circ} \mathrm{C}\right)$, the methylated fatty acids were spotted at the bottom of the plate. Plates were developed twice in a tank saturated with hexane/diethyl ether/ acetic acid (95:4:1, v/v/v) as developing solvent. After the plates had been sprayed with dichlorofluoresceine ( $0.1 \%$ in 2-propanol), the bands were visualized under UV. The bands corresponding with saturated (SFA), trans monounsaturated, and cis (c) monounsaturated (MUFA) fatty acids were scraped off in test tubes (one tube for SFA + tMUFA and one tube for cMUFA). Fatty acids were extracted from the silica gel using $1.5 \mathrm{~mL}$ of $\mathrm{MeOH}, 2 \mathrm{~mL}$ of hexane, and $1.5 \mathrm{~mL}$ of a $\mathrm{NaCl}$ solution $(5 \%)$. After the fatty acids had been dried under $\mathrm{N}_{2}$, they were redissolved in hexane and kept at $-20{ }^{\circ} \mathrm{C}$ in vials until analysis. For the separation of the individual tMUFA and cMUFA by gas chromatography, the following conditions were used: oven temperature, 170 ${ }^{\circ} \mathrm{C}$ isothermal; $\mathrm{H}_{2}$ as carrier gas, using a CP-Sil88 column for FAME $(100 \mathrm{~m} \times 0.25 \mathrm{~mm} \times 0.2 \mu \mathrm{m}$, Chrompack). Individual tMUFA and cMUFA were identified using the retention times of the corresponding standards (t9C18:1, t11C18:1, t12C18:1, t13C18:1, c9C18:1, c11C18: 1) (Sigma, Bornem, Belgium). For the identification of t10C18:1, t14C18:1, t15C18:1, t16C18:1, c12C18:1, and c13C18:1 the interpretation was based on the elution sequence of the different isomers as reported by Wolff (18) and Precht and Molkentin (19).

3. Estimation of Lipolysis and Biohydrogenation in the Rumen Samples. Lipolysis in the rumen samples of groups GC and MC was estimated by separating the total lipid extracts into free fatty acids, triacylglycerols, and polar lipids by thin-layer chromatography (20), followed by gas chromatography to determine the fatty acid profile of the different lipid classes. Aliquot volumes of the extracts were evaporated under $\mathrm{N}_{2}$ and redissolved in $150 \mu \mathrm{L}$ of chloroform. After the plates covered with silica gel $\mathrm{G}$ had been activated $\left(1 \mathrm{~h}\right.$ at $\left.103{ }^{\circ} \mathrm{C}\right)$, the lipids were spotted on the plates. Plates were developed in closed tanks saturated with hexane/diethyl ether/acetic acid (70:30:2; v/v/v). After the plates had been sprayed with dichlorofluoresceine $(0.1 \%$ in 2-propanol), the bands were visualized under UV, and those corresponding to the triacylglycerols, free fatty acids and polar lipids were scraped off. Lipids were extracted from the silica gel with chloroform/ methanol $(1: 2, \mathrm{v} / \mathrm{v})$ followed twice by chloroform/methanol $(1: 1, \mathrm{v} / \mathrm{v})$, methylated, and analyzed by gas chromatography as described above. Lipolysis of the $\mathrm{C} 18$ fatty acids was calculated as the ratio of free $\mathrm{C} 18$ fatty acids $\times 100 /$ (free C18 fatty acids + C18 fatty acids in the triacylglycerols $+\mathrm{C} 18$ fatty acids in the polar lipids). Only lipolysis of $\mathrm{C} 18$ fatty acids was considered in this study, because only unsaturated fatty acids are hydrogenated and the majority of dietary unsaturated fatty acids have an 18-carbon chain length. It has been shown that biohydrogenation of unsaturated fatty acids can take place only after liberation of the fatty acids in the free form from the triacylglycerols and polar lipids in the process of lipolysis (2).

4. Determination of Volatile Fatty Acids (VFA) in Rumen Contents. Immediately after collection, rumen contents were filtered through a metallic sieve (mesh width of $1 \mathrm{~mm}$ ) and acidified with formic acid/ phosphoric acid $(1: 10, \mathrm{v} / \mathrm{v})$ (final concentration $=2 \%)$. Acidified samples were centrifuged (10 $\mathrm{min}$ at $22000 \mathrm{~g}$, MSE, Amsterdam, The Netherlands) and filtered, and the filtrate was used for VFA analysis by gas chromatography $(21)$.

Statistical Analysis. The effect of feeding group on the fatty acid composition of the different sample types was analyzed by ANOVA. 
Table 1. Fat Content (Grams of Fat per $100 \mathrm{~g}$ of Dry Matter) and Pattern of the Main Fatty Acids (Grams per $100 \mathrm{~g}$ of Total Fatty Acids) of the Diet Fed during the Fattening Phase

\begin{tabular}{|c|c|c|c|c|c|c|c|}
\hline & \multirow{2}{*}{$\frac{\text { group } C^{e}}{\text { conc }^{a}}$} & \multicolumn{3}{|c|}{ group GCe } & \multicolumn{3}{|c|}{ group MCe } \\
\hline & & conc & $\mathrm{R}^{b}$ & complete $\operatorname{diet}^{c}$ & conc & $\mathrm{R}$ & complete diet \\
\hline $\begin{array}{l}\text { conc/ } R^{d} \\
\text { concentrate }\end{array}$ & $\begin{array}{l}100 \\
\text { no linseed }\end{array}$ & & $\begin{array}{l}70 / 30 \\
\text { arass silage }\end{array}$ & & & $\begin{array}{l}80 / 20 \\
\text { maize silage }\end{array}$ & \\
\hline $\begin{array}{l}\text { concentrate } \\
\text { fat content }\end{array}$ & & linseed based & & & linseed based & & \\
\hline $\begin{array}{l}\text { fat content } \\
\mathrm{g} / 100 \mathrm{~g} \text { of total fatty acids }\end{array}$ & 3.89 & 6.80 & 2.45 & 5.15 & 7.54 & 6.63 & 7.33 \\
\hline C14:0 & 0.26 & 0.11 & 0.90 & 0.25 & 0.53 & 0.31 & 0.48 \\
\hline C16:0 & 14.4 & 8.74 & 26.8 & 12.0 & 12.5 & 16.6 & 13.4 \\
\hline C18:0 & 4.60 & 3.30 & 4.41 & 3.50 & 10.8 & 1.52 & 8.87 \\
\hline C18:1 & 16.3 & 17.0 & 5.31 & 14.9 & 15.8 & 22.9 & 17.3 \\
\hline C18:2n-6 & 47.1 & 24.7 & 12.6 & 22.5 & 28.2 & 41.4 & 30.9 \\
\hline$C 18: 3 n-3$ & 12.3 & 43.2 & 33.5 & 41.4 & 28.8 & 3.13 & 23.5 \\
\hline
\end{tabular}

${ }^{a}$ Conc $=$ concentrate component. ${ }^{b} \mathrm{R}=$ roughage component. ${ }^{c}$ Fat content and fatty acid composition of the complete diet (concentrate + roughage) was calculated based on the measured daily intake. ${ }^{d}$ Conc/R ratio on dry matter basis following formulations (conc/R ratio of real intake was slightly different). ${ }^{e}$ Group $\mathrm{C}$, concentrate diet (without linseed in the fattening phase); group GC, concentrate (with linseed in the fattening phase)-grass silage diet; group MC, concentrate (with linseed in the fattening phase)-maize silage diet.

Table 2. Fatty Acid Composition of the Rumen Content Depending on the Feeding Group ${ }^{a}$

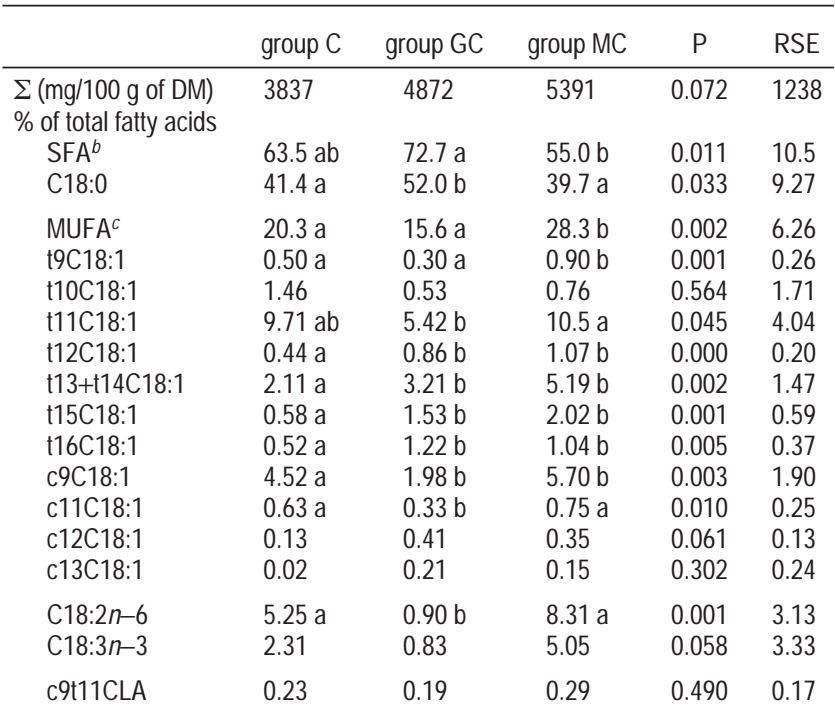

${ }^{a}$ Means with different letters are significantly different $(P<0.05)$. Group $C$, concentrate diet (without linseed in the fattening phase); group GC, concentrate (with linseed in the fattening phase)-grass silage diet; group MC, concentrate (with linseed in the fattening phase)-maize silage diet. ${ }^{b} \mathrm{SFA}=\mathrm{C} 12: 0+\mathrm{C} 14: 0$ $+\mathrm{C} 15: 0+\mathrm{C} 16: 0+\mathrm{C} 17: 0+\mathrm{C} 18: 0+\mathrm{C} 20: 0+\mathrm{C} 22: 0 .{ }^{C} \mathrm{MUFA}=\mathrm{C} 14: 1+\mathrm{C} 15: 1$ $+\mathrm{C} 17: 1+\mathrm{C} 18: 1+\mathrm{C} 20: 1$.

The Duncan post-hoc test was used for comparison of the mean values. Pearson linear correlation coefficients were also calculated. All calculations were done using SPSS (22).

\section{RESULTS}

Fatty Acid Composition of the Diets. Table 1 provides a detailed fatty acid profile of the diets of the fattening period according to the three different groups. Due to differences in the diet composition [see full description of all diets in Raes et al. (14)] the fatty acid compositions of the diets are different for the different groups.

Fatty Acid Profile of the Digesta. Tables 2 and $\mathbf{3}$ show the fatty acid compositions of the rumen and abomasal contents, respectively. Abomasal contents contained more extractable fatty acids than rumen contents, irrespective of the feeding groups. Group $\mathrm{C}$ had a lower rumen fat content $(P>0.05)$ and a lower abomasal fat content $(P>0.05)$ compared with groups GC and
Table 3. Fatty Acid Composition of the Abomasal Content Depending on the Feeding Groupa

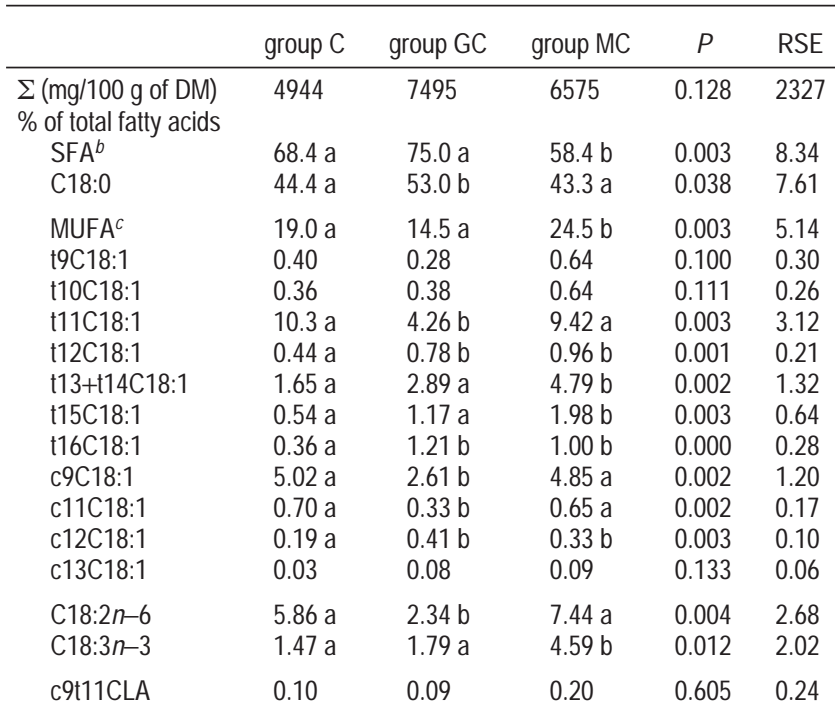

${ }^{a}$ Means with different superscripts are significantly different $(P<0.05)$. Group $\mathrm{C}$, concentrate diet (without linseed in the fattening phase); group GC, concentrate (with linseed in the fattening phase)-grass silage diet; group MC, concentrate (with linseed in the fattening phase)-maize silage diet. ${ }^{b} \mathrm{SFA}=\mathrm{C} 12: 0+\mathrm{C} 14: 0$ $+\mathrm{C} 15: 0+\mathrm{C} 16: 0+\mathrm{C} 17: 0+\mathrm{C} 18: 0+\mathrm{C} 20: 0+\mathrm{C} 22: 0 .{ }^{\circ}$ MUFA $=\mathrm{C} 14: 1+\mathrm{C} 15: 1$ $+\mathrm{C} 17: 1+\mathrm{C} 18: 1+\mathrm{C} 20: 1$

MC, reflecting the lower dietary fat level (Table 1). Group GC showed in both digestive contents a higher saturated fatty acid (SFA) proportion $(P<0.05$ and $P<0.01$ for rumen and abomasal contents, respectively), a lower monounsaturated fatty acid (MUFA) proportion ( $P<0.01$ for both digestive contents), mainly due to a lower $\mathrm{C} 18: 1$ proportion, and lower $\mathrm{C} 18: 2 n-6$ $(P<0.001$ and $P<0.01$ for rumen and abomasal contents, respectively) and C18:3n-3 $(P>0.05$ and $P<0.05$ for rumen and abomasal contents, respectively) proportions compared to groups $\mathrm{C}$ and $\mathrm{MC}$. No differences among the feeding groups were observed in c9t11CLA proportion in rumen and abomasal contents $(P>0.05)$, whereas the t10c12CLA isomer was not detected in the digestive contents. Within the tC18:1 isomers, t11C18:1 was the most abundant one in the digestive contents $(5-10 \mathrm{~g} / 100 \mathrm{~g}$ of total fatty acids), followed by t13+t14C18:1 (1.5-5 g/100 $\mathrm{g}$ of total fatty acids). Group GC had a significantly lower proportion of $111 \mathrm{C} 18: 1$, whereas group $\mathrm{C}$ 
Table 4. Volatile Fatty Acid Production in the Rumen According to the Different Feeding Groups ${ }^{a}$

\begin{tabular}{|c|c|c|c|c|c|}
\hline & group C & group GC & group MC & $P$ & RSE \\
\hline $\begin{array}{l}\text { VFA (mmol/L of } \\
\text { rumen content) } \\
\mathrm{mmol} / \mathrm{mol} \text { of total VFA }\end{array}$ & 12491 & 10605 & 10219 & 0.096 & 2811 \\
\hline acetate & $581 \mathrm{a}$ & $691 \mathrm{~b}$ & $538 \mathrm{c}$ & 0.000 & 45.3 \\
\hline propionate & $281 a$ & $171 \mathrm{~b}$ & $276 a$ & 0.000 & 46.6 \\
\hline butyrate & 90.0 & 99.5 & 103 & 0.314 & 20.2 \\
\hline valerate & $26.1 \mathrm{a}$ & $10.4 \mathrm{~b}$ & $41.5 \mathrm{C}$ & 0.000 & 11.2 \\
\hline
\end{tabular}

${ }^{a}$ Means with different superscripts are significantly different $(P<0.05)$. Group $C$, concentrate diet (without linseed in the fattening phase); group GC, concentrate (with linseed in the fattening phase)-grass silage diet; group MC, concentrate (with linseed in the fattening phase)-maize silage diet.

Table 5. Fatty Acid Composition of the Subcutaneous Fat Depending on the Feeding Group ${ }^{2}$

\begin{tabular}{lccccc}
\hline & group C & group GC & group MC & $P$ & RSE \\
\hline $\begin{array}{l}\sum \text { (mg/g of fat) } \\
\text { \% of total fatty acids }\end{array}$ & 828 & 811 & 754 & 0.214 & 81.4 \\
SFA & & & & & \\
C18:0 & 44.0 & 43.6 & 45.3 & 0.356 & 2.40 \\
MUFA & 14.6 & 15.0 & 15.6 & 0.188 & 2.43 \\
t9C18:1 & 45.7 & 45.9 & 46.1 & 0.948 & 2.23 \\
t10C18:1 & 0.24 & 0.28 & 0.31 & 0.551 & 0.11 \\
t11C18:1 & 0.37 & 0.77 & 0.44 & 0.201 & 0.41 \\
t12C18:1 & 4.44 & 3.20 & 4.50 & 0.215 & 1.48 \\
t13+t14C18:1 & $0.41 \mathrm{a}$ & $0.64 \mathrm{~b}$ & $0.51 \mathrm{ab}$ & 0.025 & 0.14 \\
t15C18:1 & $1.25 \mathrm{a}$ & $2.32 \mathrm{~b}$ & $1.66 \mathrm{~b}$ & 0.001 & 0.41 \\
t16C18:1 & $0.31 \mathrm{a}$ & $0.78 \mathrm{~b}$ & $0.41 \mathrm{a}$ & 0.000 & 0.16 \\
c9C18:1 & $0.33 \mathrm{a}$ & $0.95 \mathrm{~b}$ & $0.23 \mathrm{a}$ & 0.000 & 0.24 \\
c11C18:1 & 32.3 & 30.8 & 32.8 & 0.486 & 3.16 \\
c12C18:1 & $1.34 \mathrm{a}$ & $1.01 \mathrm{~b}$ & $1.45 \mathrm{a}$ & 0.003 & 0.21 \\
c13C18:1 & $0.32 \mathrm{a}$ & $0.48 \mathrm{~b}$ & $0.36 \mathrm{a}$ & 0.001 & 0.06 \\
C18:2n-6 & 0.22 & 0.20 & 0.20 & 0.921 & 0.07 \\
C18:3n-3 & $3.35 \mathrm{a}$ & $2.40 \mathrm{~b}$ & $3.99 \mathrm{a}$ & 0.002 & 0.74 \\
c9t11CLA & $0.93 \mathrm{a}$ & $1.47 \mathrm{~b}$ & $0.94 \mathrm{a}$ & 0.000 & 0.19 \\
& $0.65 \mathrm{a}$ & $0.93 \mathrm{~b}$ & $0.84 \mathrm{ab}$ & 0.025 & 0.18
\end{tabular}

${ }^{a}$ Means with different letters are significantly different $(P<0.05)$. Group $C$, concentrate diet (without linseed in the fattening phase); group GC, concentrate (with linseed in the fattening phase)-grass silage diet; group MC, concentrate (with linseed in the fattening phase)-maize silage diet. ${ }^{b} \mathrm{SFA}=\mathrm{C} 12: 0+\mathrm{C} 14: 0$ $+\mathrm{C} 15: 0+\mathrm{C} 16: 0+\mathrm{C} 17: 0+\mathrm{C} 18: 0+\mathrm{C} 20: 0+\mathrm{C} 22: 0 .{ }^{\circ}$ MUFA $=\mathrm{C} 14: 1+\mathrm{C} 15: 1$ $+C 17: 1+C 18: 1+C 20: 1$.

contained a lower proportion of $\mathrm{t} 12 \mathrm{C} 18: 1, \mathrm{t} 13+\mathrm{t} 14 \mathrm{C} 18: 1$, t15C18:1, and t16:1C18:1. The $\mathrm{cC} 18: 1$ isomer proportion, with c9C18:1 the most abundant one, was much lower than the tC18:1 isomer proportion.

Volatile Fatty Acid Proportions in the Rumen. Table 4 gives the VFA proportions measured in the rumen contents depending on the feeding group. Similar concentrations of total VFA were measured in the three groups. However, the acetate (HAC) proportion significantly differed among the three groups and increased in the order $\mathrm{MC}<\mathrm{C}<\mathrm{GC}$, whereas valerate differed significantly in the opposite order. The proprionate (HPr) proportion was significantly lower for group GC compared to the groups $\mathrm{C}$ and $\mathrm{MC}$, which did not differ. No differences between the groups in butyrate were measured.

Subcutaneous, Intramuscular, and Liver Fatty Acid Profile. Compared to the fatty acid profile of the rumen and abomasal contents, a lower SFA proportion was observed in the subcutaneous, intramuscular, and liver fat (Tables 5, 6, and 7 , respectively). The subcutaneous and intramuscular fat contained a much higher amount of cC18:1 isomers (mainly c9C18: 1) compared to the rumen and abomasal contents (Tables 5
Table 6. Fatty Acid Composition of the Intramuscular Fat of the Longissimus Thoracis Depending on the Feeding Groupa

\begin{tabular}{llllll}
\hline & group C & group GC & group MC & $P$ & RSE \\
\hline $\begin{array}{l}\sum \text { (mg/100 g of muscle) } \\
\text { \% of total fatty acids }\end{array}$ & 674 & 838 & 651 & 0.230 & 228 \\
SFA & & & & & \\
C18:0 & 33.1 & 36.9 & 34.5 & 0.099 & 3.25 \\
MUFA & $13.7 \mathrm{a}$ & $15.7 \mathrm{~b}$ & $14.2 \mathrm{ab}$ & 0.038 & 1.45 \\
t9C18:1 & 25.3 & 29.8 & 26.9 & 0.195 & 4.82 \\
t10C18:1 & 0.13 & 0.19 & 0.19 & 0.068 & 0.05 \\
t11C18:1 & 0.35 & 0.52 & 0.26 & 0.156 & 0.26 \\
t12C18:1 & 2.53 & 1.92 & 3.12 & 0.096 & 1.05 \\
t13+t14C18:1 & $0.20 \mathrm{a}$ & $0.43 \mathrm{~b}$ & $0.35 \mathrm{~b}$ & 0.000 & 0.08 \\
t15C18:1 & $0.94 \mathrm{a}$ & $1.64 \mathrm{~b}$ & $1.24 \mathrm{a}$ & 0.002 & 0.33 \\
t16C18:1 & $0.18 \mathrm{a}$ & $0.47 \mathrm{~b}$ & $0.39 \mathrm{~b}$ & 0.000 & 0.10 \\
c9C18:1 & $0.16 \mathrm{a}$ & $0.47 \mathrm{~b}$ & $0.27 \mathrm{c}$ & 0.000 & 0.07 \\
c11C18:1 & 18.7 & 22.5 & 20.1 & 0.202 & 3.95 \\
c12C18:1 & $1.73 \mathrm{a}$ & $1.03 \mathrm{~b}$ & $1.62 \mathrm{a}$ & 0.001 & 0.32 \\
c13C18:1 & $0.20 \mathrm{a}$ & $0.42 \mathrm{~b}$ & $0.34 \mathrm{~b}$ & 0.005 & 0.11 \\
$\sum_{n} n-6{ }^{d}$ & 0.14 & 0.11 & 0.11 & 0.700 & 0.07 \\
C18:2n-6 & $24.0 \mathrm{a}$ & $14.6 \mathrm{~b}$ & $21.9 \mathrm{a}$ & 0.001 & 4.49 \\
$\sum n-3^{\mathrm{e}}$ & $18.3 \mathrm{a}$ & $11.1 \mathrm{~b}$ & $16.6 \mathrm{a}$ & 0.001 & 3.35 \\
C18:3n-3 & $4.74 \mathrm{a}$ & $6.89 \mathrm{~b}$ & $4.83 \mathrm{a}$ & 0.008 & 1.36 \\
c9t11CLA & $1.73 \mathrm{a}$ & $3.71 \mathrm{~b}$ & $2.42 \mathrm{c}$ & 0.000 & 0.57 \\
& $0.32 \mathrm{a}$ & $0.49 \mathrm{~b}$ & $0.47 \mathrm{~b}$ & 0.027 & 0.12
\end{tabular}

${ }^{a}$ Means with different letters are significantly different $(P<0.05)$. Group $C$, concentrate diet (without linseed in the fattening phase); group GC, concentrate (with linseed in the fattening phase)-grass silage diet; group MC, concentrate (with linseed in the fattening phase)-maize silage diet. ${ }^{b} \mathrm{SFA}=\mathrm{C} 12: 0+\mathrm{C} 14: 0$ $+\mathrm{C} 15: 0+\mathrm{C} 16: 0+\mathrm{C} 17: 0+\mathrm{C} 18: 0+\mathrm{C} 20: 0+\mathrm{C} 22: 0 .{ }^{c}$ MUFA $=\mathrm{C} 14: 1+\mathrm{C} 15: 1$ $+\mathrm{C} 17: 1+\mathrm{C} 18: 1+\mathrm{C} 20: 1 .{ }^{d} \sum n-6=\mathrm{C} 18: 2 n-6+\mathrm{C} 18: 3 n-6+\mathrm{C} 20: 3 n-6+\mathrm{C} 20:$ $4 n-6+\mathrm{C} 22: 4 n-6 .{ }^{e} \Sigma n-3=\mathrm{C} 18: 3 n-3+\mathrm{C} 18: 4 n-3+\mathrm{C} 20: 5 n-3+\mathrm{C} 22: 5 n-3+$ $\mathrm{C} 22: 6 n-3$.

Table 7. Fatty Acid Composition of the Liver Depending on the Feeding Group ${ }^{a}$

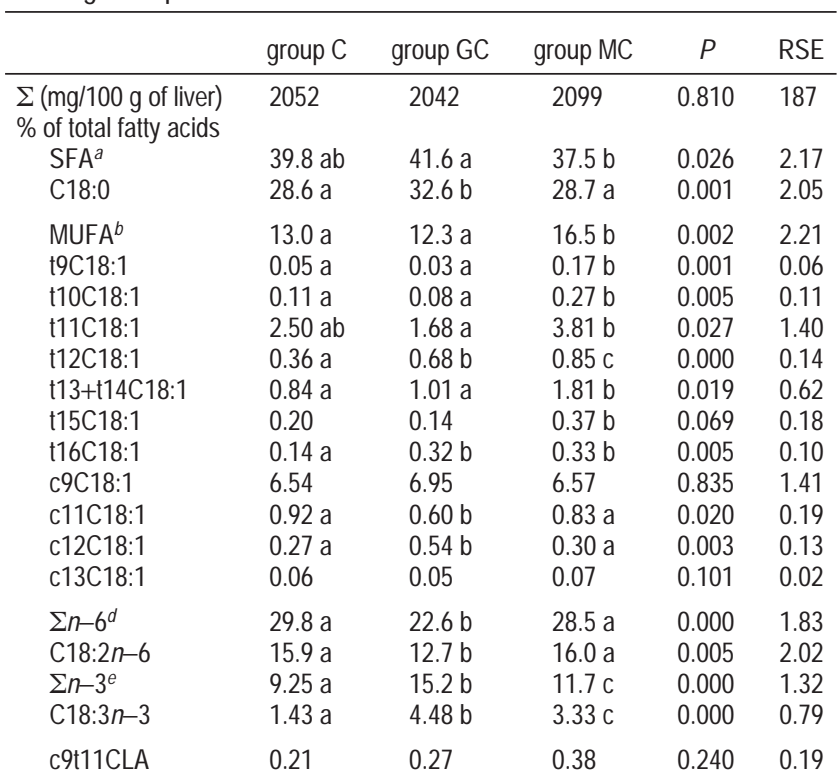

${ }^{a}$ Means with different letters are significantly different $(P<0.05)$. Group $C$, concentrate diet (without linseed in the fattening phase); group GC, concentrate (with linseed in the fattening phase)-grass silage diet; group MC, concentrate (with linseed in the fattening phase)-maize silage diet. ${ }^{b} \mathrm{SFA}=\mathrm{C} 12: 0+\mathrm{C} 14: 0$ $+\mathrm{C} 15: 0+\mathrm{C} 16: 0+\mathrm{C} 17: 0+\mathrm{C} 18: 0+\mathrm{C} 20: 0+\mathrm{C} 22: 0 .{ }^{c}$ MUFA $=\mathrm{C} 14: 1+\mathrm{C} 15: 1$ $+\mathrm{C} 17: 1+\mathrm{C} 18: 1+\mathrm{C} 20: 1{ }^{d}{ }^{d} n-6=\mathrm{C} 18: 2 n-6+\mathrm{C} 18: 3 n-6+\mathrm{C} 20: 3 n-6+\mathrm{C} 20:$ $4 n-6+\mathrm{C} 22: 4 n-6 .{ }^{e} \Sigma n-3=\mathrm{C} 18: 3 n-3+\mathrm{C} 18: 4 n-3+\mathrm{C} 20: 5 n-3+\mathrm{C} 22: 5 n-3+$ C22:6n-3.

and 6 versus Tables $\mathbf{2}$ and $\mathbf{3}$ ), whereas for the liver only a small increase in c9C18:1 was observed for group GC (Table 7 versus 
Table 8. Ratio of c9t11CLA/t11C18:1 in Rumen Content and Fat Tissues Depending on Feeding Group ${ }^{a}$

\begin{tabular}{lllll}
\hline & group C & group GC & group MC & $P$ \\
\hline rumen content & 0.06 & 0.04 & 0.03 & 0.571 \\
subcutaneous fat & $0.19 \mathrm{a}$ & $0.32 \mathrm{~b}$ & $0.15 \mathrm{a}$ & 0.001 \\
intramuscular fat & $0.20 \mathrm{ab}$ & $0.29 \mathrm{a}$ & $0.17 \mathrm{~b}$ & 0.037 \\
liver fat & 0.20 & 0.27 & 0.13 & 0.171
\end{tabular}

\footnotetext{
${ }^{a}$ Means with different letters are significantly different $(P<0.05)$. Group $C$, concentrate diet (without linseed in the fattening phase); group GC, concentrate (with linseed in the fattening phase)-grass silage diet; group MC, concentrate (with linseed in the fattening phase)-maize silage diet.
}

Tables 2 and 3). Although the $\mathrm{tC} 18: 1$ profiles of the three tissues seem to show a profile similar to that of the digestive contents, a lower proportion of $111 \mathrm{C} 18: 1$ ( $2-5$ times) was noted in the subcutaneous, intramuscular, and liver fat. Except for the c9t11CLA, no other CLA isomers were detected. The c9t11CLA proportion was clearly higher in intramuscular and subcutaneous fat (overall means of 0.43 and $0.82 \mathrm{~g} / 100 \mathrm{~g}$ of total fatty acids, respectively) compared to the digestive contents $(0.24$ and 0.13 $\mathrm{g} / 100 \mathrm{~g}$ of total fatty acids, respectively, for rumen and abomasal contents), whereas the content of c9t11CLA in the liver was still somewhat lower $(0.29 \mathrm{~g} / 100 \mathrm{~g}$ of total fatty acids $)$.

Endogenous Synthesis of c9t11CLA. The ratio of c9t11CLA/ t11C18:1 was calculated to have an idea about the relationship between precursor and end-product and to provide indirectly an estimation of the $\Delta^{9}$-desaturase activity (Table 8). Results of abomasal contents are not presented as the c9t11CLA content was highly variable between animals within groups, resulting in a very high variation in the ratio c9t11CLA/t11C18:1. The ratio is 5-10 times higher in rumen contents than in the tissues. Group $\mathrm{C}$ had a higher c9t11CLA/t11C18:1 ratio in rumen content $(P>0.05)$, as well as in subcutaneous $(P<0.01)$, intramuscular $(P<0.05)$, and liver $(P>0.05)$ fat compared to the other groups.

\section{DISCUSSION}

The study described here is part of a larger experiment aiming at investigating the effect of dietary fatty acids on the intramuscular fatty acid composition. Hence, the experimental design is not fully appropriate to study the transformations of dietary fatty acids in the digestive tract and the intermediary metabolism. No fistulated animals were used; hence, no digestive flows could be measured. In addition, diets were shifted during the experiment according to the different phases in the animal production. It was shown that this affected the intramuscular fatty acid composition, especially with respect to the incorporation of the longer chain fatty acids (14). It should be realized that the fatty acid profiles of the digesta are a reflection of the intake and rumen metabolism of fatty acids in the last days prior to slaughter (diet of the fattening phase, microorganisms, digestive state), whereas the fatty acid composition of the subcutaneous, intramuscular, and liver fat is a global reflection of the livelong fatty acid metabolism of the animal. Nevertheless, it is believed that a comparison of the fatty acid profiles of different samples and tissues may reveal some insight into fatty acid metabolism.

Fatty Acid Profile of the Digestive Contents. 1. Comparison of the Fatty Acid Profile of Rumen and Abomasal Contents. The fatty acid profiles of rumen and abomasal contents are well correlated for individual tC18:1 isomers ( $r$ between 0.49 and 0.92, except for t10C18:1), total tC18:1 $(r=0.88)$, total C18:1 $(r=0.99)$, c9t11CLA $(r=0.67), \mathrm{C} 18: 2 n-6$ and C18:3n-3 $(r$ $=0.84$ and 0.89 , respectively), and total fatty acids, SFA, and
MUFA ( $r=0.64,0.95$, and 0.98 respectively). These good correlations suggest that sampling of both abomasal and rumen contents was carried out properly, resulting in representative samples.

The higher fat content of the abomasal content compared with the rumen samples confirmed former results that in the rumen fat is not degraded by the microorganisms (23). This is in contrast with carbohydrates, proteins, and starch, which are degraded and partially converted to volatile products, which can be absorbed by the rumen wall. Taking this into account, the abomasal digesta is enriched in fat compared to rumen contents.

The c9t11CLA content in the abomasal digesta was highly variable, and because of its very low levels in abomasal digesta, the quantification of the isomer was difficult. Combinations of other purification and separation techniques (such as $\mathrm{Ag}^{+}$HPLC) with analysis by gas chromatography will result most likely in a more reliable determination of the abomasal c9t11CLA level. Despite the high-concentrate diets, no t10c12CLA could be detected in rumen contents. This is in contrast with results observed in fistulated dairy cattle fed highconcentrate diets (10).

2. Accumulation of Hydrogenation Intermediates in the Rumen. High amounts of tC18:1 fatty isomers (70-80\% of total C18:1) were found in both digestive contents. The t11C18:1 proportion comprised $38.8-63.4 \%$ of total tC18:1 in duodenal digesta, which is in agreement with observations of Bickerstaffe et al. (23), who found that $57 \%$ of total tC18:1 was the t11 isomer. The fatty acid composition of the feed (high C18:3n-3 content) as well as the diet composition (roughage and concentrate composition) seems to have an influence on the distribution of the individual tC18:1 isomers as significantly higher $\mathrm{t} 13+\mathrm{t} 14 \mathrm{C} 18: 1$ and $\mathrm{t} 15 \mathrm{C} 18: 1$ contents were observed in groups $\mathrm{GC}$ and $\mathrm{MC}$ compared to group $\mathrm{C}$. Lower proportions of t15C18:1 in the rumen and abomasal contents of the diet low in C18:3n-3 (group C) confirm the role of this end-product during the biohydrogenation of $\mathrm{C} 18: 3 n-3$, as suggested by Harfoot and Hazlewood (2). Similarly, t13+t14C18:1 was lowest for group $\mathrm{C}$, which is in accordance with the accumulation of $113 \mathrm{C} 18: 1$ during in vitro incubations of pure $\mathrm{C} 18: 3 n-3$ (Jouany, personal communication).

3. Rumen Biohydrogenation of C18:2n-6 and C18:3n-3 in Relation to the Diet. Complete biohydrogenation of C18:2n-6 and $\mathrm{C} 18: 3 n-3$ in the rumen results in an accumulation of $\mathrm{C} 18: 0$ and in $115 \mathrm{C} 18: 1$ and $\mathrm{c} 15 \mathrm{C} 18: 1$ for $\mathrm{C} 18: 3 n-3$ (2). Biohydrogenation might be reduced indirectly by the inhibition of lipolysis, induced, for example, by low $\mathrm{pH}$ values (24) or the use of ionophores (25), or directly-with the accumulation of free fatty acids - through increased amounts of fat, in particular C18:2n-6 (26) or C20 and C22 unsaturated fatty acids (27). Also, the physical or chemical protection of dietary fats could affect lipolysis and biohydrogenation. Accordingly, direct inhibition of the rumen biohydrogenation process also might result in the accumulation of intermediates such as trans isomers or conjugated dienes as free fatty acids.

Very low proportions of C18:2n-6 and C18:3n-3, relatively high proportions of SFA, and a low proportion of MUFA in the rumen contents of animals of group GC suggest a more complete hydrogenation of both $\mathrm{C} 18: 2 n-6$ and $\mathrm{C} 18: 3 n-3$. Nevertheless, total C18 lipolysis did not differ between both groups [83.0 (SD 3.7)\% and 79.8 (SD 10.3)\% for groups GC and $\mathrm{MC}$, respectively]. Reduced lipolysis might be induced when the rumen $\mathrm{pH}$ falls below 5.5 (24). Although the rumen $\mathrm{pH}$ was not measured, similar concentrations of VFA suggest minor $\mathrm{pH}$ differences between the diets. Nevertheless, the more 
complete hydrogenation in association with the GC diet might be due to an altered rumen environment-and associated microbial population - as suggested from the rumen VFA pattern (higher HAC and lower HPR contents for group GC). Eventually, differences in particulate structure of the rumen contents, induced by differences in the physical structure of the roughage compound of the diet, might have altered rumen lipolysis and biohydrogenation because feed particles seem to play some role in both processes $(2,28)$. Additionally, a complete absence of rumen protozoa was observed in group MC, although this was not reflected in a reduced butyrate proportion. However, as the role of protozoa in rumen lipolysis and hydrogenation is minor (2), it is doubtful that this might explain the observed differences among the three diets.

Subcutaneous, Intramuscular, and Liver Fatty Acid Profiles. Higher MUFA and lower SFA proportions in the subcutaneous and intramuscular fat compared with the rumen digesta reflect the activity of the $\Delta^{9}$-desaturase, the enzyme responsible for the conversion of SFA (C14:0, C16:0, and C18: 0) to the corresponding MUFA (c9C14:1, c9C16:1, and c9C18: 1). St. John et al. (29) demonstrated that in ruminants the activity of the $\Delta^{9}$-desaturase was much higher in subcutaneous fat microsomes than in the liver microsomes, supporting our observation that the liver was not enriched in MUFA compared to the rumen digesta.

Total tC18:1 fatty acids for muscle and subcutaneous fat were 5.41 (SD 1.45) and 8.28 (SD 2.52) g/100 g of total fatty acids, respectively. These values are in agreement with other studies analyzing trans fatty acids in beef and are somewhat higher for subcutaneous fat $(18,30,31)$. Data for the distribution of the individual tC18:1 isomers of subcutaneous and intramuscular fat are similar to those obtained by Bayard and Wolff (31) except for $\mathrm{t} 13+\mathrm{t} 14 \mathrm{C} 18: 1$ isomers, which is higher in our study. Comparison between our data and those of the other studies mentioned is difficult as information on age, sex, breed, and nutrition of the animals is lacking. Furthermore, reported effects of diets on the tC18:1 profile in ruminant digesta and milk are not always consistent. Griinari et al. (7) have shown that the concentration of $\mathrm{t} 12 \mathrm{C} 18: 1$ and $\mathrm{t} 13+\mathrm{t} 14 \mathrm{C} 18: 1$ in milk was not influenced by the diet, whereas Piperova et al. (4) have demonstrated that low-forage diets significantly increased all trans C18:1 isomers in the duodenal flow and t9C18:1, t10C18: 1, $\mathrm{t} 13+\mathrm{t} 14 \mathrm{C} 18: 1$, and $\mathrm{t} 15 \mathrm{C} 18: 1$ in milk. The latter finding was confirmed by LeDoux et al. (32), who reported dietary effects on some tC18:1 isomers in goat's milk.

Endogenous Synthesis of c9t11CLA. Despite the fact that in all groups similar and low levels of c9t11CLA were found in rumen digesta, the proportion of c9t11CLA was increased in the subcutaneous and intramuscular fat and was higher when linseed was added as an $n-3$ source in the fattening diet (groups GC and MC). A clear reduction in tC18:1 fatty acids, especially in $111 \mathrm{C} 18: 1$, was noted in the subcutaneous, intramuscular, and liver fat compared to the digesta sample. A strong correlation for the precursor (t11C18:1) and end-product (t11C18:1+c9t11CLA) exists $(r=0.803)$. However, this high correlation is mainly due to a strong relationship between t11C18:1 in the rumen and in the intramuscular fat $(r=0.845)$ and not by the relationship between $111 \mathrm{C} 18: 1$ or c9t11CLA in the rumen and c9t11CLA in the intramuscular fat $(r=0.119$ and 0.220 , respectively).

The data strongly suggest that, after its absorption, a significant part of $111 \mathrm{C} 18: 1$ is converted to c9t11CLA by $\Delta^{9}$ desaturase, the enzyme responsible for the endogenous synthesis of c9t11CLA in bovine adipose tissue (29). These observations together with the much higher ratio in c9t11CLA/t11C18:1 in subcutaneous and intramuscular fat compared to rumen contents suggest that the endogenous synthesis of c9t11CLA in adipose tissue is much more important than its ruminal production. Similarly, Griinari et al. (10) showed that the endogenous c9t11CLA synthesis in the mammary gland contributes most importantly to c9t11CLA. The significantly higher ratio c9t11CLA/t11C18:1 in group GC is probably the result of the lower $\mathrm{t} 11 \mathrm{C} 18: 1$ accumulation in the rumen. Taking into account the higher $\mathrm{t} 11 \mathrm{C} 18: 1$ content of the digesta of group $\mathrm{C}$ compared with group GC, a higher c9t11CLA content in subcutaneous and intramuscular fat would be expected for group C. However, the opposite was observed; that is, group GC had higher amounts of c9t11CLA in the tissues. These differences between diets and the above-mentioned low correlation between t11C18:1 and c9t11CLA suggest that the ruminal outflow of t11C18:1 is important but is not the rate-limiting step for c9t11CLA formation in subcutaneous or intramuscular fat. Other factors that can influence the activity of the $\Delta^{9}$-desaturase may include end-product inhibition by c9t11CLA, the ratio of C18:2n-6/ C18:3n-3, or the individual contents of $n-6$ or $n-3$ fatty acids. It is indeed known that PUFA can affect and regulate desaturase activity (see the review in ref 33).

In accordance with the low activity of the bovine liver desaturase (29) and a low MUFA content, no increase of c9t11CLA was measured in the liver compared to the rumen contents.

Conclusions. Feeding high amounts of C18:2n-6 and C18: $3 n-3$ resulted in an extensive hydrogenation of these fatty acids with an accumulation of $\mathrm{tC} 18: 1$ isomers in the digesta, mainly as $\mathrm{t} 11 \mathrm{C} 18: 1$. Besides $\mathrm{t} 11 \mathrm{C} 18: 1$, a whole range of $\mathrm{tC} 18: 1$ isomers was formed in the rumen and was also deposited in subcutaneous, intramuscular, and liver fat. The levels of tC18:1 isomers were clearly lower in the latter tissue compared to rumen and abomasal contents, whereas the subcutaneous and intramuscular fat were enriched in cC18:1 fatty acids, mainly as c9C18:1. The results suggest that endogenous synthesis of c9t11CLA in adipose tissue is much more important than its production in the rumen and that this endogenous synthesis may not be limited by the intestinal supply of $11 \mathrm{C} 18: 1$.

\section{ACKNOWLEDGMENT}

We thank INVE Technologies (Baasrode, Belgium) for advice in feed formulations and for supply of the $n-3$ premix. J. Latré and the staff of the secondary school KTA (Diksmuide, Belgium) are thanked for their assistance with the animal trial and the slaughtering and cutting of the animals. We are grateful for the technical assistance of S. Coolsaet, P. Dhaeyere, and D. Baeyens.

\section{LITERATURE CITED}

(1) Demeyer, D. Lipidstoffwechsel im Pansen. In Biologie und Biochemie der mikrobiellen Verdauung; Giesecke, D., Henderickx, H. K., Eds.; BLV Verlaggesellschaft: München, Germany, 1973; pp 209-234.

(2) Harfoot, C. G.; Hazlewood, G. P. Lipid metabolism in the rumen. In The Rumen Microbial Ecosystem; Hobson, P. N., Ed.; Elsevier Applied Science: New York, 1988; pp 382-426.

(3) Griinari, J. M.; Bauman, D. E. Biosynthesis of conjugated linoleic acid and its incorporation into meat and milk in ruminants. In Advances in Conjugated Linoleic Acid Research; Yurawecz, M. P., Mossoba, M. M., Kramer, J. K. G., Pariza, M. W., Nelson, G. J., Eds.; AOCS Press: Champaign, IL, 1999; Vol. 1, pp 180200. 
(4) Piperova, L. S.; Sampugna, J.; Teter, B. B.; Kalscheur, K. F.; Yurawecz, M. P.; Ku, Y.; Morehouse, K. M.; Erdman, R. A. Duodenal and milk trans octadecenoic acid and conjugated linoleic acid (CLA) isomers indicate that postabsorptive synthesis is the predominant source of cis-9-containing CLA in lactating dairy cows. J. Nutr. 2002, 132, 1235-1241.

(5) Proell, J. M.; Mosley, E. E.; Powell, G. L.; Jenkins, T. C. Isomerization of stable isotopically labeled elaidic acid to cis and trans monoenes by ruminal microbes. J. Lipid Res. 2002, 43, 2072-2076.

(6) Ward, P. F. V.; Scott, T. W.; Dawson, R. M. C. The hydrogenation of unsaturated fatty acids in the ovine digestive tract. Biochem. J. 1964, 92, 60-68.

(7) Griinari, J. M.; Dwyer, M. A.; McGuire, M. A.; Bauman, D. E.; Palmquist, D. L.; Nurmela, K. V. V. Trans-octadecenoic acids and milk fat depression in lactating dairy cows. J. Dairy Sci. 1998, 81, 1251-1261.

(8) Kalscheur, K. F.; Teter, B. B.; Piperova, L. S.; Erdman, R. A. Effect of dietary forage concentration and buffer addition on duodenal flow of trans C18:1 fatty acids and milk fat production in dairy cows. J. Dairy Sci. 1997, 80, 2104-2114.

(9) Mosley, E. E.; Powell, G. L.; Riley, M. B.; Jenkins, T. C. Microbial biohydrogenation of oleic acid to trans isomers in vitro. J. Lipid Res. 2002, 43, 290-296.

(10) Griinari, J. M.; Corl, B. A.; Lacy, S. H.; Chouinard, P. Y.; Nurmela, K. V. V.; Bauman, D. E. Conjugated linoleic acid is synthesized endogenously in lactating dairy cows by $\Delta^{9}$ desaturase. J. Nutr. 2000, 130, 2285-2291.

(11) Dhiman, T. R.; Anand, G. R.; Satter, L. D.; Pariza, M. W. Conjugated linoleic acid content of milk from cows fed different diets. J. Dairy Sci. 1999, 82, 2146-2156.

(12) Enser, M.; Scollan, N. D.; Choi, N. J.; Kurt, E.; Hallet, K.; Wood, J. D. Effect of dietary lipid on the content of conjugated linoleic acid (CLA) in beef muscle. Anim. Sci. 1999, 69, 143-146.

(13) French, P.; Stanton, C.; Lawless, F.; O’Riordan, E. G.; Monahan, F. J.; Caffrey, P. J.; Moloney, A. P. Fatty acid composition, including conjugated linoleic acid, of intramuscular fat from steers offered grazed grass, grass silage or concentrate based diets. J. Anim. Sci. 2000, 78, 2849-2855.

(14) Raes, K.; De Smet, S.; Balcaen, A.; Claeys, E.; Demeyer, D. Effect of diets rich in n-3 polunsaturated fatty acids on muscle lipids and fatty acids in Belgian Blue double-muscled young bulls. Reprod. Nutr. Dev. 2003, 43, 331-345.

(15) Folch, J.; Lees, M.; Stanley, G. H. S. A simple method for the isolation and purification of total lipids from animal tissues. $J$. Biol. Chem. 1957, 226, 497-509.

(16) Raes, K.; De Smet, S.; Demeyer, D. Effect of double-muscling in Belgian Blue young bulls on the intramuscular fatty acid composition with emphasis on conjugated linoleic acid and polyunsaturated fatty acids. Anim. Sci. 2001, 73, 253-260.

(17) Christie, W. W., Ed. Gas Chromatography and Lipids; The Oily Press: Dundee, U.K., 1989; 307 pp.

(18) Wolff, R. L. Content and distribution of trans-18:1 acids in ruminant milk and meat fats. Their importance in European diets and their effect on human milk. J. Am. Oil Chem. Soc. 1995, 72, 259-272.

(19) Precht, D.; Molkentin, J. Rapid analysis of the isomers of transoctadecenoic acid in milk fat. Int. Dairy J. 1996, 6, 791-809.
(20) Demeyer, D. I.; Henderson, C.; Prins, R. A. Relative significance of exogenous and de novo synthesized fatty acids in the formation of rumen microbial lipids in vitro. Appl. Environ. Microbiol. 1978, 35, 24-31.

(21) Van Nevel, C. J.; Demeyer, D. I. Effect of monensin on rumen metabolism in vitro. Appl. Environ. Microbiol. 1977, 34, 251257.

(22) SPPS Software for Windows, release 10.0; SPSS Inc., Chicago, IL.

(23) Bickerstaffe, R.; Noakes, D. E.; Annison, E. F. Quantitative aspects of fatty acid biohydrogenation, absorption and transfer into milk in the lactating goat, with special reference to the cisand trans-isomers of octadecenoate and linoleate. Biochem. J. 1972, 130, 607-617.

(24) Van Nevel, C. J.; Demeyer, D. I. Effect of pH on biohydrogenation of polyunsaturated fatty acids and their Ca-salts by rumen micro-organisms in vitro. Arch. Anim. Nutr. 1996, 49, 151157.

(25) Fellner, V.; Sauer, F. D.; Kramer, J. K. G. Effect of nigericin, monensin and tetronasin on biohydrogenation in continuous flowthrough ruminal fermenters. J. Dairy Sci. 1997, 80, 921-928.

(26) Harfoot, C. G.; Noble, R. C.; Moore, J. H. Factors influencing the extent of biohydrogenation of linoleic acid by rumen microorganisms in vitro. J. Sci. Food Agric. 1973, 24, 961-970.

(27) Dohme, F.; Fievez, V. I.; Raes, K.; Demeyer, D. I. Increasing levels of two different fish oils lower ruminal biohydrogenation of eisopentaenoic and docosahexaenoic acid in vitro. Anim. Res. 2003, 52, 309-320.

(28) Gerson, T.; King, A. S. D.; Kelly, K. E.; Kelly, W. J. Influence of particle size and surface area on in vitro rate of gas production, lipolysis of triacylglycerol and hydrogenation of linoleic acid by sheep rumen digesta of Ruminococcus flavefaciens. J. Agric. Sci. (Cambridge) 1988, 110, 31-37.

(29) St. John, L. C.; Lunt, D. K.; Smith, S. B. Fatty acid elongation and desaturation enzyme activities of bovine liver and subcutaneous adipose tissue microsomes. J. Anim. Sci. 1991, 75, 15251533.

(30) Aro, A.; Antoine, J. M.; Pizzoferrato, L.; Reykdal, O.; van Poppel, G. Trans fatty acids in dairy and meat products from 14 European countries: the TRANSFAIR study. J. Food Compos. Anal. 1998, 11, 150-160.

(31) Bayard, C. C.; Wolff, R. L. Analysis of trans C18:1 isomer content and profile in edible refined beef tallow. J. Am. Oil Chem. Soc. 1996, 73, 531-533.

(32) LeDoux, M.; Rouzeau, A.; Bas, P.; Sauvant, D. Occurrence or trans C18:1 fatty acid isomers in goat milk: effect of two dietary regimens. J. Dairy Sci. 2002, 85, 190-197.

(33) Jump, D. B. Dietary polyunsaturated fatty acids and regulation of gene transcription. Curr. Opin. Lipidol. 2000, 13, 155-164.

Received for review September 25, 2003. Revised manuscript received June 17, 2004. Accepted July 14, 2004. This research was financially supported by the Ministry of Small Enterprises, Traders and Agriculture and by the EU Community (Project QLRT-2000-31423, "Healthy Beef'). D.A. acknowledges the receipt of a grant given by the Ministerio de Educacion y Cultura (Dirección general de Universidades).

JF035089H 